\title{
Respiratory syncytial virus in young children: community cohort study integrating serological surveys, questionnaire and electronic health records, Born in Bradford cohort, England, 2008 to 2013
}

Ania Zylbersztejn ${ }^{1}$, Lucy Pembrey ${ }^{2}$, Harvey Goldstein ${ }^{1}$, Guy Berbers ${ }^{3}$, Rutger Schepp ${ }^{3}$, Fiona van der Klis ${ }^{3}$, Charles Sande ${ }^{4}$, Dan Mason ${ }^{5}$, John Wright ${ }^{5}$, Rosalind Smyth ${ }^{6}$, Pia Hardelid ${ }^{1}$

1. Population, Policy \& Practice Research and Teaching Department, UCL Great Ormond Street Institute of Child Health, London, United Kingdom

2. Medical Statistics Department, London School of Hygiene and Tropical Medicine, London, United Kingdom

3. Centre of Infectious Disease Control, National Institute of Public Health and the Environment (RIVM), Bilthoven, the Netherlands

4. Kemri-Wellcome Trust Research Programme, Kilifi, Kenya

5. Bradford Institute for Health Research, Bradford Teaching Hospitals NHS Foundation Trust, Bradford, United Kingdom

6. Infection, Immunity and Inflammation Research and Teaching Department, UCL Great Ormond Street Institute of Child Health, London, United Kingdom

Correspondence: Ania Zylbersztein (ania.zylbersztejn@ucl.ac.uk)

Zylbersztejn Ania, Pembrey Lucy, Goldstein Harvey, Berbers Guy, Schepp Rutger, van der Klis Fiona, Sande Charles, Mason Dan, Wright John, Smyth Rosalind, Hardelid Pia. Respiratory syncytial virus in young children: community cohort study integrating serological surveys, questionnaire and electronic health records, Born in Bradford cohort, England, 2008 to 2013. Euro Surveill. 2021;26(6):pii=2000023. https://doi.org/10.2807/1560-7917.ES.2021.26.6.2000023

\section{Introduction}

Respiratory syncytial virus (RSV) is a major cause of respiratory morbidity and mortality in young children, accounting for over 33 million episodes of acute lower respiratory tract infection in children under 5 years old per year globally $[1,2]$. In the United Kingdom (UK), as in many other high-income countries, RSV bronchiolitis is the most common reason for hospitalisation in infants [3]. Infection in early life has been associated with an increased risk of wheeze-related illness throughout childhood [4].

There are currently no RSV vaccines available, although a number of candidates are in clinical trials [5]. Several factors related to the clinical and virological features of RSV challenge the design of an effective vaccination programme, including the very young age at which children are vulnerable to severe RSV morbidity (RSVrelated hospital admissions in the UK peak at 1 month of age $[6,7])$. Further, the short period of immunity induced by natural RSV infection [8], and the seasonal pattern of acute bronchiolitis admissions in temperate countries mean that a successful vaccine will need to induce a stronger immune response than that induced by natural infection $[9,10]$. In order to determine who should be vaccinated, and when, to effectively protect young children from infection, detailed data on risk of infection according to age and other characteristics, including family structure, are required.
Community-based serological surveys provide crucial data for understanding the epidemiology of RSV, including the proportion of RSV-infected children who are asymptomatic, or who contact healthcare. A community cohort study of children in Kilifi, Kenya has provided insights into RSV dynamics that informed economic modelling of RSV vaccine programmes in low income settings $[11,12]$. A number of serological surveys of RSV have been carried out in high income settings [13-15]. However, these studies have limited data on risk factors for RSV infection in young children, such as family structure.

We describe the epidemiology of RSV during the first 2 years of life in a cohort of children born in Bradford, UK. Using a unique longitudinal dataset combining serial serological data, parental questionnaires and routinely collected primary care and hospital records, we establish factors associated with maternallyderived antibody concentrations, the proportion of children infected with RSV, their associated healthcare use, and risk factors for RSV infection by age.

\section{Methods}

\section{Data source}

We used data from the Born in Bradford (BiB) cohort study, a longitudinal multi-ethnic birth cohort of 12,453 mothers and 13,773 children recruited in 2007-2011 in Bradford [16]. Upon recruitment, women filled in a 
TABLE 1

Description of variables included in analyses of mean maternally-derived antibody concentrations and risk of primary RSV infection at ages $<1$ and 1-2 years, England, 2008-2013

\begin{tabular}{|c|c|c|c|}
\hline Variable description & Age at measurement & Data source & Variable derivation or categorisation \\
\hline Annual quarter of birth & Birth & Maternity records & $\begin{array}{c}\text { January-March; April-June, July-September; } \\
\text { October-December }\end{array}$ \\
\hline Parity & Birth & Maternity records & $0 ; 1 ; 2 ; \geq 3$ \\
\hline Ethnicity & Birth & Baseline questionnaire & White British; Pakistani origin; other \\
\hline Sex & Birth & Maternity records & Boy/girl \\
\hline Gestational age $^{a}$ & Birth & Maternity records & $<35 ; 35-36 ; 37-40 ; \geq 41$ weeks \\
\hline Birth weight $^{\mathrm{a}}$ & Birth & Maternity records & $\langle 2,500 ; 2,500-3,499 ; \geq 3,500 \mathrm{~g}$ \\
\hline Gestational diabetes $^{a}$ & Birth & Maternity records & Yes/no \\
\hline History of hypertension ${ }^{a}$ & Birth & Maternity records & $\begin{array}{l}\text { Yes/no } \\
\text { (defined as presence of hypertension, pregnancy- } \\
\text { induced hypertension or preeclampsia) }\end{array}$ \\
\hline Household size ${ }^{b}$ & $\begin{array}{l}1 \text { and } 2 \text { years } \\
\text { ( } 2 \text { variables) }\end{array}$ & $\begin{array}{c}\text { ALL-IN questionnaires } \\
\text { at } 1 \text { and } 2 \text { year } \\
\end{array}$ & $2-4$ or $\geq 5$ household members \\
\hline Sharing a bedroom ${ }^{b}$ & $\begin{array}{l}\text { 0-5 months, } \\
\text { 6-11 months, } \\
\text { 12-23 months } \\
\text { (3 variables) }\end{array}$ & $\begin{array}{l}\text { ALL-IN questionnaires } \\
\text { at } 1 \text { and } 2 \text { year }\end{array}$ & Yes/no \\
\hline Attending formal childcare ${ }^{b}$ & $\begin{array}{l}\text { 0-11 months, } \\
\text { 12-23 months } \\
\text { (2 variables) }\end{array}$ & $\begin{array}{l}\text { ALL-IN questionnaires } \\
\text { at } 1 \text { and } 2 \text { year }\end{array}$ & $\begin{array}{l}\text { Yes/no } \\
\text { (defined as attending nursery or being cared for by a } \\
\text { childminder/nanny) }\end{array}$ \\
\hline Attending mother-baby activities ${ }^{\mathrm{b}}$ & $\begin{array}{l}\text { 6-11 months, } \\
12-23 \text { month } \\
\text { (2 variables) }\end{array}$ & $\begin{array}{l}\text { ALL-IN questionnaires } \\
\text { at } 1 \text { and } 2 \text { year }\end{array}$ & Rarely/once a week or more often \\
\hline $\begin{array}{l}\text { RTI-related contact with healthcare } \\
\text { during RSV season before blood } \\
\text { measurement }^{\text {b }}\end{array}$ & $\begin{array}{l}\text { Any contact for }<1 \text { and } \\
1-2 \text { years olds }\end{array}$ & $\begin{array}{l}\text { Linked primary care } \\
\text { and hospital records }\end{array}$ & Yes/no \\
\hline
\end{tabular}

ALL-IN: Allergy and Infection sub-study; RSV: respiratory syncytial virus; RTI: respiratory tract infection.

a Indicates variables used only for analyses of mean maternally-derived antibody concentrations.

${ }^{b}$ Indicates variables used only for analyses of risk of RSV infection.

Unless otherwise specified (footnotes $a$ and $b$ above), variables were used in both sets of analyses.

baseline questionnaire; cord blood samples were collected at birth. Cohort follow-up is via linkage to electronic health records, including maternity, primary care and hospital records for mothers and children. A subset of mothers whose babies were born on or after 1 March 2008 took part in the BiB Allergy and Infection (ALL-IN) sub-study [17], which collected additional questionnaires about the family and home environment from 2,562 children at age 1 and 2,067 at age 2 years. A total of $5 \mathrm{~mL}$ venous blood samples were collected from $1,884(74 \%)$ and 1,623 (79\%) children aged 1 and 2 years old, respectively.

\section{Inclusion criteria}

We included all children from the ALL-IN study who had sufficient serial blood samples remaining at the age 1 and 2 years (490 children) [17]. To examine maternally-derived RSV antibody concentrations (that is, antibodies transferred from mother to baby during pregnancy), we additionally tested 210 cord samples from children in the $\mathrm{BiB}$ cohort, oversampling children born prematurely (resulting in 700 total cord blood samples). Sample size calculations are presented in Supplementary material 1.

\section{Serological testing}

Blood samples were tested for immunoglobulin G (IgG) antibody against RSV postfusion protein $F$ (post $F$ ), and attachment protein $\mathrm{G}$ for RSV strands $\mathrm{A}(\mathrm{Ga})$ and $\mathrm{B}(\mathrm{Gb})$, referred to as IgG post-F, IgG Ga and IgG Gb, respectively, throughout the paper, at the National Institute of Public Health and the Environment (Bilthoven, the 


\section{FIGURE 1}

Distribution of loge RSV IgG post-F antibodies (A) at birth ( $\mathrm{n}=700$ cord blood samples), (B) age 1 ( $\mathrm{n}=490 \mathrm{children})$ and (C) 2 years old ( $n=490$ children), England, 2008-2013

\section{A. Cord blood}

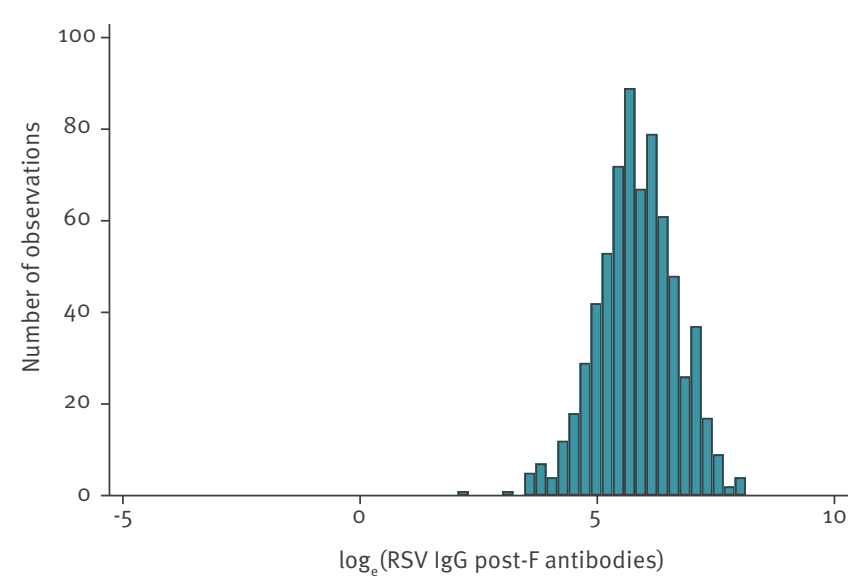

C. Aged 2 years old

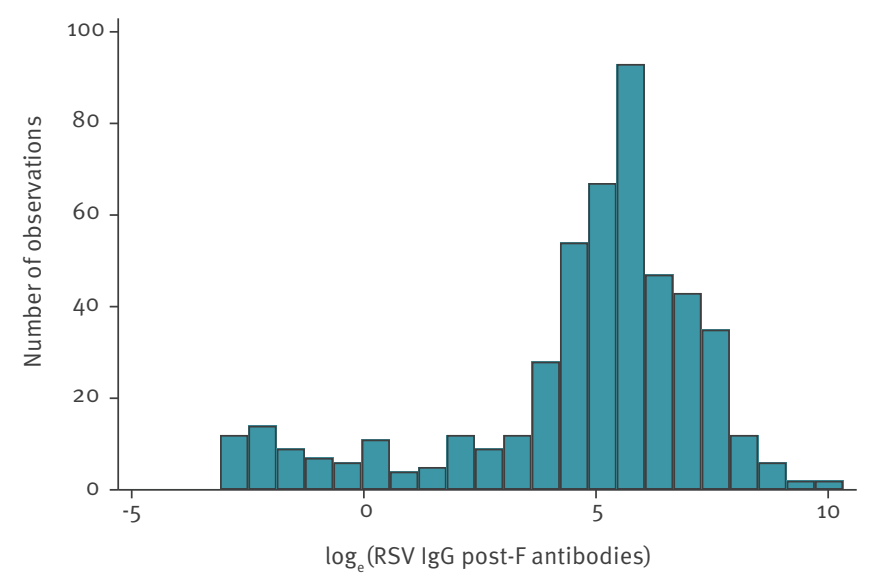

B. Aged 1 year old

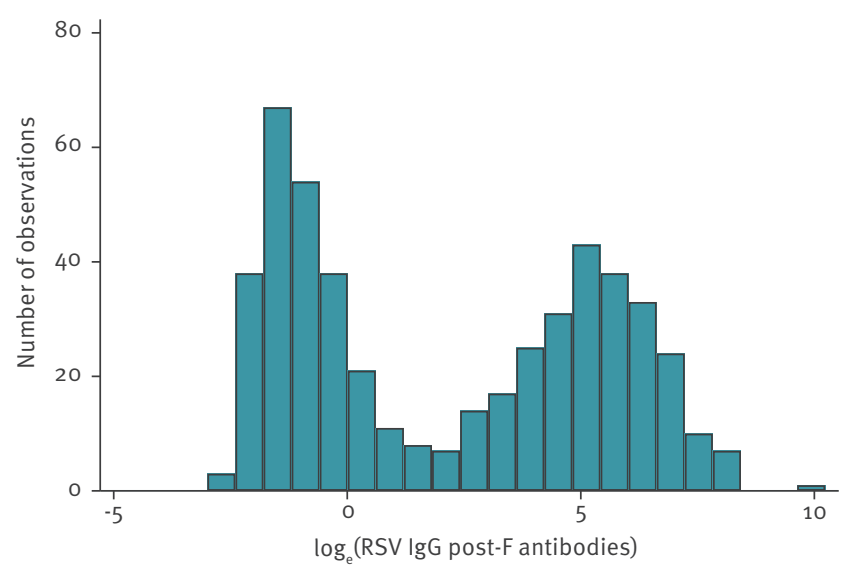

IgG post-F: immunoglobulin G antibody against RSV postfusion protein F; $\log _{\mathrm{e}}$ : natural logarithm (base e); RSV: respiratory syncytial virus.

IgG post-F concentrations were quantified in arbitrary units $/ \mathrm{mL}$.

Netherlands) using an RSV multiplex immunoassay (details described elsewhere [18]). In short, each of the three RSV antigens were coupled to distinct colour-coded activated carboxylated beads. Serum samples were diluted $1 / 200$ and $1 / 8,000$ in assay buffer containing phosphate-buffered saline with $1 \%$ bovine serum albumin and $0.1 \%$ Tween 20 , incubated with the conjugated beads and subsequently incubated with R-phycoerythrin-labelled goat anti-human IgG antibody. The measurement of the samples was performed using a Bio-Plex 200 in combination with Bio-Plex Manager software version 6.1 (Bio-Rad Laboratories, Hercules, California, United States). The serum IgG antibody concentrations against post-F, $\mathrm{Ga}$ and $\mathrm{Gb}$ were quantified in arbitrary units/mL by interpolation from a five-parameter logistic curve of an in-house reference serum.

\section{Outcomes}

Our primary outcomes of interest were RSV IgG post$\mathrm{F}$ antibody concentrations, measured in cord blood, and infection status at age $<1$ and $1-2$ years old derived from IgG post-F levels. Our secondary outcomes were RSV IgG Ga and Gb antibody concentrations. All antibody concentrations were log-transformed for analysis.

\section{Exposure variables}

Study variables are described in Table 1 . All analyses included a priori annual quarter of birth (to account for seasonality of RSV, which peaks in early December in the UK), parity, ethnic group and child's sex. For analyses of maternally-derived antibody concentrations, we additionally included risk factors which could affect placental antibody transfer. For analyses of infection status at age $<1$ and $1-2$ years, we were additionally interested in indicators of population mixing that we derived from responses to ALL-IN questionnaires at ages 1 and 2 years old, and age at measurement 
Risk factors associated with increase in mean maternally-derived RSV IgG post-F antibody levels, England, 2008-2013 $(\mathrm{n}=683 \text { children })^{\mathrm{a}}$

\begin{tabular}{|c|c|c|c|}
\hline \multirow[t]{2}{*}{ Risk factor } & \multicolumn{2}{|c|}{$\begin{array}{l}\text { Distribution of children included in the analyses by each } \\
\text { risk factor }(n=683)^{\mathrm{b}}\end{array}$} & \multirow{2}{*}{$\begin{array}{l}\text { Adjusted ratios of geometric mean maternally-derived IgG } \\
\text { post-F antibody levels }(95 \% \mathrm{Cl}))^{\mathrm{c}, \mathrm{d}}\end{array}$} \\
\hline & $\mathrm{N}$ & $\%$ & \\
\hline \multicolumn{4}{|c|}{ Gestational age (weeks) } \\
\hline$<35$ & 29 & 4.2 & $0.65(0.48-0.89)$ \\
\hline $35-36$ & 47 & 6.9 & $0.90(0.70-1.16)$ \\
\hline 37-40 (baseline) & 480 & 70.3 & 1 (baseline) \\
\hline$\geq 41$ & 127 & 18.6 & $1.19(1.01-1.39)$ \\
\hline \multicolumn{4}{|l|}{ Parity } \\
\hline o (baseline) & 227 & 33.2 & 1 (baseline) \\
\hline 1 & 203 & 29.7 & $1.20(1.03-1.40)$ \\
\hline 2 & 124 & 18.2 & $1.18(0.99-1.42)$ \\
\hline$\geq 3$ & 129 & 18.9 & $1.08(0.90-1.30)$ \\
\hline \multicolumn{4}{|l|}{ Time of birth } \\
\hline Jan-Mar & 186 & 27.2 & $1.19(1.00-1.42)$ \\
\hline Apr-Jun & 165 & 24.2 & $1.22(1.02-1.46)$ \\
\hline Jul-Sep & 159 & 23.3 & $1.22(1.03-1.46)$ \\
\hline Oct-Dec (baseline) & 173 & 25.3 & 1 (baseline) \\
\hline
\end{tabular}

$\mathrm{Cl}$ : confidence interval; IgG post-F: immunoglobulin G antibody against RSV postfusion protein F; RSV: respiratory syncytial virus.

a The cohort included 700 children with cord blood samples, of whom 683 had complete information on all risk factors included in the final analyses of maternally-derived antibody concentrations.

b The number and percentages of children, per risk factor category included in the final model, are presented.

c The exponentiated results from the loge-linear model (mutually adjusted for all variables in the table), reflecting proportional change in maternally-derived IgG post-F levels for each risk factor category relative to the baseline are shown.

d The mean maternally-derived RSV IgG post-F antibody concentration at baseline (gestational age of $37-40$ weeks, parity of o and birth in October-December) was 268 arbitrary units $/ \mathrm{mL}$ (95\% Cl: 229-314 arbitrary units $/ \mathrm{mL}$ ).

(in months). We derived a binary variable indicating whether the child had had contact with primary or hospital care due to lower or unspecified respiratory tract infection (RTI) during peak RSV season (NovemberJanuary) before blood measurement (from linked electronic health records, see Supplementary material 1 for a detailed definition).

\section{Statistical analyses}

We derived the number and proportion of children in our study and in the full ALL-IN cohort by risk factors at birth, age 1 and 2 years old.

Maternally-derived respiratory syncytial virus antibody concentrations

We derived mean maternally-derived $\log _{e}$ RSV IgG post-F antibody concentrations according to each risk factor category (listed in Table 1). We fitted a log-linear regression model to identify exposures associated with higher mean maternally-derived RSV IgG post-F levels. We determined factors associated with $\log _{\mathrm{e}}$ RSV IgG post- $F$ antibody concentrations in univariate analyses using analysis of variance (ANOVA). We included all risk factors significantly associated with placental antibody transfer in univariate analyses in the multivariable model (where $p<0.05$ ); we excluded those that were not statistically significant in the mutually adjusted model from the final multivariable model according to Wald's test (where p>0.05).
Primary respiratory syncytial virus infection at ages 1 and 2 years old

We applied a two-stage modelling strategy to determine risk factors for RSV infection. First, we used finite mixture models (FMM) to classify children as RSV infected at age 1 year and 1-2 years respectively according to their $\log _{e}$ RSV IgG post- $F$ levels at age 1 and 2 years old. FMM is a well-established data driven method for classifying past exposure to infection $[19,20]$. FMM assume that the observed sample comes from distinct unobserved subpopulations. We expected two subpopulations (infected/not-infected). The model was as follows:

Where $\left(\pi_{1}, \pi_{2}\right)$ are probabilities of belonging to each subpopulation, and $\left(f_{1}, f_{2}\right)$ are density functions for antibody concentrations in each subpopulation. For antibodv concentrations at age 2. we allowed $f\left(\log _{e}(\mathrm{RSV}\right.$ IgG post-F $\left.)\right)=\pi_{1} \times f_{1}\left(\log _{e}(\mathrm{RSV}\right.$ IgG post-F $\left.)\right)+\pi_{2} \times f_{2}\left(\log _{e} \ln (\mathrm{RSV}\right.$ IgG post-F $\left.)\right)$

$\left(\pi_{1}, \Pi_{2}\right)$ to depend on observed antibody concentrations at age 1. Details of FMM selection are described in Supplementary material 1.

For each child, we then derived a binary indicator of serological evidence of past RSV infection as:

Where $p_{i}$ is the posterior probability of infection from FMM for child $i$. Throughout the paper we refer to 


\section{FIGURE 2}

Distribution of primary RSV infections in children by age at first infection and severity of infection (as indicated by contact with healthcare), England, 2008-2013 ( $n=490$ children)

Serological evidence of any RSV infection by age 2 years:

$422 / 490$ children ( $86 \%$ of sampled children; $95 \% \mathrm{Cl}: 83-89 \%$ )

Serological evidence of first infection at age $<1$ year: Serological evidence of first infection at age $1-2$ years:

\begin{tabular}{r|l}
258 children & 164 children \\
\hline $53 \%$ (95\% Cl: 48-57\%) of sampled children & $33 \%$ (95\% Cl: $29-38 \%)$ of sampled children \\
\hline $61 \%$ (95\% Cl: $56-66 \%)$ of ever infected children & $39 \%$ (95\% Cl: $34-44 \%)$ of ever infected children
\end{tabular}

Contacted primary or hospital care during RSV season (October-February) prior to blood measurement

\begin{tabular}{r|l}
128 children & 79 children \\
$26 \%(95 \% \mathrm{Cl}: 22-30 \%)$ of sampled children & $16 \%(95 \% \mathrm{Cl}: 13-20 \%)$ of sampled children \\
$50 \%$ (95\% Cl: $43-56 \%)$ of children & $48 \%(95 \% \mathrm{Cl}: 40-56 \%)$ of children \\
first infected at age <1 year & first infected at age $1-2$ years
\end{tabular}

Contacted primary or hospital care during peak RSV season (November-January) prior to blood measurement

$\begin{aligned} 99 \text { children } & 58 \text { children } \\ 20 \%(95 \% \mathrm{Cl}: 17-24 \%) \text { of sampled children } & 12 \%(95 \% \mathrm{Cl}: 9.1-15 \%) \text { of sampled children } \\ 38 \%(95 \% \mathrm{Cl}: 34-43 \%) \text { of children } & 35 \%(95 \% \mathrm{Cl}: 28-43 \%) \text { of children } \\ \text { first infected at age <1 year } & \text { first infected at age 1-2 years }\end{aligned}$

Admitted to hospital during peak RSV season (November-January) prior to blood measurement

\begin{tabular}{r|r}
9 children & $<5$ children \\
$1.8 \%(95 \% \mathrm{Cl}: 0.8 \%-3.5 \%)$ of sampled children & $<1 \%(95 \% \mathrm{Cl}: 0.3-2.4 \%)$ of sampled children \\
$3.5 \%(95 \% \mathrm{Cl}: 1.6 \%-6.5 \%)$ of children & $<3 \%(95 \% \mathrm{Cl}: 1.0-7.0 \%)$ of children \\
first infected at age $<1$ year & first infected at age $1-2$ years
\end{tabular}

$\mathrm{Cl}$ : confidence interval; RSV: respiratory syncytial virus.

Left-hand side shows the number and proportion of children first infected aged <1year old, right-hand side show the proportion of children first infected aged 1-2 years old (that is, they were never infected at age 1 ). We present the number of children who contacted healthcare using a broad definition of RSV season (October-February) and peak RSV season (November-January).

presence of serological evidence of past RSV infection from the FMM as 'RSV infection'. We calculated the number and proportion of children who acquired pri-

$$
R S V \text { Infection }_{i}=\left\{\begin{array}{l}
1 \text { if } p_{i} \geq 0.5 \\
0 \text { otherwise }
\end{array}\right.
$$

mary RSV infection aged / 1 year and 1-2 years old. We derived the proportion of infected (seropositive) and seronegative children who had RTI-related contact with healthcare during peak RSV season. We compared the distribution of risk factors in RSV-infected and neverinfected children by age.

We estimated risk ratios (RR) for primary RSV infection at age $<1$ and $1-2$ years old using Poisson regression models with robust error variances calculated using sandwich estimators [21]. We decided a priori to include child's age at blood sample measurement and annual quarter of birth, sex and ethnicity in the models. We added all indicators of population mixing to the model (listed in Table 1). Then we removed those that were not statistically significant according to Wald's test (where $p>0.05$ ).
Sensitivity analyses

Infections in infants aged $<6$ months old may not be detectable using serology, as young infants do not mount an antibody response to infection (or their response might be 'masked' by maternally-derived antibodies) [22-24]. We therefore repeated all analyses after re-classifying children who had RTI-related contact with healthcare aged 66 months during RSV season (October-February) and during peak RSV season (November-January) as infected at age<1 year.

To account for possible misclassification of infection status arising from using a cut-off for the posterior probability of infection from the FMM, $p_{i}$, we simulated the infection status for each child $i$ as a random draw from Bernoulli distribution with $p$, taken as the probability of success. We then re-calculated RR for primary infection. We repeated this 50 times and pooled estimates of RRs using Rubin's rules for the parameter estimates and variance-covariance matrix [25]. We repeated all analyses using $\log _{e}$ RSV IgG Ga and Gb. All analyses were carried out using Stata version 15. 
TABLE 3

Adjusted risk ratios for primary RSV infection at age 1 and 2 years old by risk factor, England, 2008-2013 (n=477)

\begin{tabular}{|c|c|c|}
\hline Risk factor & $\begin{array}{c}\text { Adjusted risk ratios for primary RSV infection } \\
\text { at age } 11 \text { year old }(95 \% \mathrm{Cl})^{\mathrm{b}}\end{array}$ & $\begin{array}{c}\text { Adjusted risk ratios for primary RSV infection } \\
\text { at age } 1-2 \text { years old }(95 \% \mathrm{Cl})^{\mathrm{b}}\end{array}$ \\
\hline Number of children included in the model & 477 & 229 \\
\hline Number of infected children & 248 & 162 \\
\hline \multicolumn{3}{|l|}{ Sex } \\
\hline Male (baseline) & 1 (baseline) & 1 (baseline) \\
\hline Female & $1.07(0.91-1.27)$ & $1.12(0.95-1.32)$ \\
\hline \multicolumn{3}{|l|}{ Ethnic group } \\
\hline White British (baseline) & 1 (baseline) & 1 (baseline) \\
\hline Pakistani origins & $1.23(0.98-1.55)$ & $0.88(0.73-1.05)$ \\
\hline Other & $1.27(0.95-1.69)$ & $1.01(0.80-1.28)$ \\
\hline \multicolumn{3}{|l|}{ Annual quarter of birth } \\
\hline Jul-Sep (baseline) & 1 (baseline) & 1 (baseline) \\
\hline Oct-Dec & $1.57(1.19-2.08)$ & $1.23(1.02-1.48)$ \\
\hline Jan-Mar & $1.57(1.18-2.09)$ & $1.12(0.89-1.41)$ \\
\hline Apr-Jun & $1.63(1.22-2.18)$ & $0.77(0.54-1.09)$ \\
\hline \multicolumn{3}{|l|}{ Parity } \\
\hline o (baseline) & 1 (baseline) & 1 (baseline) \\
\hline 1 & $1.49(1.18-1.87)$ & $1.27(1.04-1.56)$ \\
\hline 2 & $1.22(0.93-1.60)$ & $1.20(0.93-1.56)$ \\
\hline$\geq 3$ & $1.38(1.06-1.79)$ & $1.34(1.05-1.70)$ \\
\hline \multicolumn{3}{|l|}{ Attending any formal childcare } \\
\hline No (baseline) & 1 (baseline) & \multirow{2}{*}{ Not included in the final model } \\
\hline Yes & $1.36(1.09-1.69)$ & \\
\hline Age at measurement ${ }^{c}$ & $1.08(1.00-1.16)$ & $1.02(0.96-1.08)$ \\
\hline
\end{tabular}

$\mathrm{Cl}$ : confidence interval; RSV: respiratory syncytial virus.

a Of 490 children whose blood samples were tested for immunoglobulin G antibody against RSV postfusion protein F, 477 ( $97 \%$ ) had complete information for the analysis of risk factors for primary RSV infection at age <1 year old. Of these, 229 had not experienced an infection in infancy and were included for the analysis of risk factors for primary RSV infection at age 1-2 years.

${ }^{b}$ Risk ratios for primary RSV infection by each risk factor were estimated from Poisson regression models with robust error variances calculated using sandwich estimator.

Age at measurement was centred around 12 months for risk ratios for primary RSV infection at age $<1$ year, and around 24 months for risk ratios for primary RSV infection at age $1-2$ years.

\section{Ethical statement}

Parents in BIB and ALL-IN studies have given informed consent for use of data and stored blood samples for research studies. The ALL-IN study has been approved by the Bradford Research Ethics Committee, reference number 08/H1302/21.

\section{Results}

The cohort included 700 children with cord blood samples, of whom 683 (98\%) had complete information on all risk factors included in the final analyses of maternally-derived antibody concentrations. A total of 490 children had blood samples measured at both age 1 and 2 years old, of whom 477 (97\%) had complete information on risk factors included in the final analyses of risk factors for primary RSV infection. Over half of children $(55 \% ; 384 / 700)$ were of Pakistani origin compared to $49 \%(1,251 / 2,562)$ in the ALL-IN study (Supplementary

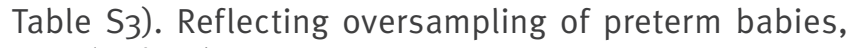
$11 \%(76 / 700)$ of the children in the cohort were born prematurely vs $5.8 \%(149 / 2,562)$ in the ALL-IN study and a third were first-born (227/700) compared to
$36 \%, 920 / 2,562$ in the ALL-IN study. Mean age at first ALL-IN questionnaire was 13.1 months (95\% confidence interval (Cl):13.0-13.2 months, Supplementary Table S4), and at second questionnaire was 25.6 months (95\% Cl:25.5-25.7 months). Maternally-derived antibodies showed an approximately normal distribution; at age 1 antibody concentrations were equally distributed around two peaks; at 2 years old, the majority of observations were centred around the higher peak (Figure 1).

\section{Maternally-derived respiratory syncytial virus antibody concentrations}

Gestational age, parity and annual quarter of birth were significantly associated with maternally-derived RSV antibody concentrations (see Supplementary Table $\mathrm{S}_{5}$ for detailed results). Children born at $<35$ gestational weeks had $35 \%$ lower, and children born at $\geq 41$ weeks had $19 \%$ higher, mean maternally-derived IgG post- $F$ levels compared with children born at 37-40 weeks (Table 2). Presence of 1-2 older siblings compared with no older siblings was associated with $18-20 \%$ higher 
mean maternally-derived antibody concentrations, and $\geq 3$ siblings with $8 \%$ higher levels. Children born outside October-December had 19-22\% higher mean maternally-derived antibody concentrations than children born during these months.

\section{Primary respiratory syncytial virus infection at} ages 1 and 2 years old

By age1year, 258/490 children (53\%; $95 \% \mathrm{Cl}: 48-57 \%$, Figure 2) had serological evidence of past RSV infection, 99 of whom had RTI-related contact with primary or hospital care in November-January (38\% of RSV infected children; 95\% Cl:34-43\%); nine had had an RTI-related hospitalisation. Of 232 children who were RSV seronegative at age 1,48 (21\%; $95 \% \mathrm{Cl}: 16-26 \%)$ had RTIrelated contact with healthcare in November-January (of whom 29 were aged $<6$ months old). A further 164 of 490 children had serological evidence of primary RSV infection at age $1-2$ years old (33\%; 95\% Cl: 29-38\%), 58 of whom had RTI-related contact with primary or hospital care in November-January (35\% of children first infected at age $1-2 ; 95 \% \mathrm{Cl}: 28-43 \%)$. A proportion of $68 / 490$ children (14\%; $95 \% \mathrm{Cl}: 11-17 \%)$ had no evidence of RSV infection by age 2, of whom 13 (19\%; 95\% Cl: $11-30 \%$ ) had RTI-related contact with primary or hospital care in November-January.

Factors associated with an increased risk of RSV infection aged<1year old were annual quarter of birth, number of older siblings, and attending formal childcare (Table 3, see Supplementary Table S6 for detailed analyses). Children with one older sibling had $49 \%$ higher risk of infection in infancy relative to children with no older siblings. Having two, or more than two, siblings increased the risk of infection by $22 \%$ and $38 \%$, respectively, compared to no siblings. Children who attended formal childcare had 36\% higher risk of infection compared with children who did not attend formal childcare. The risk of infection was $57-63 \%$ higher for children born during or after RSV season (i.e. in October-June). The risk of primary infection at age 1-2years old was greater for children with siblings compared with children with no siblings, and for children born during the RSV season (OctoberMarch, Table 3).

\section{Sensitivity analyses}

We identified an additional 40 children who had RTIrelated contact with healthcare in October-February aged $<6$ months. After re-classifying these children as infected in infancy, we estimated that $61 \%$ (299/490; 95\% Cl:57-65\%) of children were RSVinfected aged<1year, 28\% (137/490; 95\% Cl:24-32\%) were newly infected aged $1-2$ years old and $11 \%$ (54/490; $95 \% \mathrm{Cl}: 8-14 \%$ ) had no evidence of RSV infection by their second birthday. RRs did not change substantially (Supplementary Tables S7 and S8), apart from the effect of annual quarter of birth on risk of primary RSV infection in infancy, which reduced substantially for all annual quarters compared with children born in July-September. Sensitivity analyses included a higher number of RSV infections in the baseline category (born in July-September) compared with the main analyses, leading to a smaller, non-significant effect of annual quarter of birth. The pooled estimates from 50 simulated outcomes were consistent with results from the main analysis.

Analyses of maternally-derived IgG Ga and Gb showed similar results to those for IgG post-F (Supplementary Table S9). The indicator of RSV infection in infancy derived using each IgG post-F, $\mathrm{Ga}$ and $\mathrm{Gb}$ agreed for $58 \%(284 / 490)$ of children, 32\% (156/490) showed agreement between IgG post-F and either $\mathrm{Ga}$ or $\mathrm{Gb}$ antibodies (Supplementary Table S10). Since IgG Ga and $\mathrm{Gb}$ antibodies are less immunogenic than IgG post-F [18], we did not re-calculate RRs using RSV infection indicators from these models (see Supplementary material 2 for details).

\section{Discussion}

By the end of their first year of life, $53 \%$ of children experienced at least one RSV infection, $38 \%$ of whom had RTI-related contact with healthcare during peak RSV season. A further $33 \%$ of children experienced their first RSV infection aged 1-2 years old, 35\% of whom had RTI-related contact with primary or hospital care during the RSV season. One in seven children had no evidence of RSV infection by age 2. Having older siblings, attending formal childcare and birth between October and June were predictive of RSV infection at age $<1$. Having older siblings contributed to increased risk of RSV infection between 1 and 2 years. Children born at later gestational ages, in families with older siblings and after the first half of the RSV season (October-December) had higher mean maternallyderived antibody concentrations.

\section{Strengths and limitations}

We used a unique collection of longitudinal blood samples in children up to 2 years of age, linked to rich questionnaire data with information on risk factors in the child's family and home environment. Routinely collected electronic health records from primary care and hospitals provided us with indicators for more severe symptomatic RTIs leading to healthcare contact. Infection status was derived from antibody data using robust statistical methods. Instead of costly and timeconsuming data collection for a de-novo serological survey, we re-used previously collected data, minimising the costs of the study, and the burden of data collection and blood sampling on families and children.

A limitation of our study is that we were not able to validate infection status derived from FMM against confirmed RSV infections, since nasopharyngeal aspirates were not collected for the ALL-IN study. This would be useful for indicating infections in infants aged $<6$ months, who are less likely to exhibit serological response to infection [22-24]. Children<6 months old have the highest risk of developing RSV-related 
lower RTI [26], and their parents are therefore most likely to contact healthcare for their children. Therefore, our sensitivity analyses including children who had RTIrelated contact with healthcare at younger ages likely accounted for most of the early infections and showed consistent results. Further, we were not able to assess how many children were re-infected during their second year of life. Ideally, repeated swab sampling during the first 2 years of life is required to estimate the rate of reinfection.

Our study focussed on one geographical area in the UK, with a multi-ethnic, urban population. Therefore, our results may be predominantly applicable to similar settings in high income countries. Our methods, however, could be applied to residual blood samples from other cohort studies where blood samples have been collected at similar intervals for comparison.

\section{Implications}

We found that over half of children in this UK study experienced at least one RSV infection in infancy, and a further third of children had evidence of primary RSV infection between the ages of 1 and 2 years. Our estimates of the incidence of RSV in the community were comparable with a serological survey from Kilifi ( $52 \%$ of children were RSV-seropositive at age 12-15 months and $83 \%$ at age 18-24 months in 2007-2010) [27], higher than in a Finnish study (37\% had evidence of infection by age 1, 68\% by age 2 in 2009-2013) [15], and lower than the often quoted study from 1986 carried out in Houston, US [14], in which $68 \%$ of 125 infants and $91 / 92$ children aged $1-2$ years had been infected with RSV. In contrast, we found that one in seven children remained uninfected by the age of 2 . These differences could reflect differences in study settings and serological testing methods and performance (e.g. one study is now over 35 years old). Since a substantial proportion of children experienced primary infection during their second year of life, a vaccination programme for older infants with a catch-up school programme will be important in reducing the community burden of RSV [11]. A third of children with primary infection in the second year of life were in contact with primary care services. RSV infections in this older age group therefore contribute considerably to the RSV-related burden on health services, and should be taken into account in modelling studies evaluating RSV vaccination programmes.

The presence of older siblings in the household was the risk factor consistently predictive of the risk of primary RSV infection both in infancy and aged 2 years old, even after adjusting for exposure to formal childcare environments. Older siblings, in particular schoolage older siblings, are the most likely source of RSV infections in households $[11,13,28]$, and contribute to increased risk of RSV-related hospitalisation in young children [6]. Therefore, preventive strategies to reduce early infections in young children, whether public health campaigns or vaccination strategies, need to include reducing the risk of infection posed by older siblings.

Maternally-derived antibody concentrations were $20 \%$ lower for children born in the first half of RSV season (October-December) than in othermonths, but we did not observe a strong seasonal pattern as that reported for neutralising antibodies, with increases in mean RSV antibody concentrations between January-June and decreases thereafter [29]. We found that levels of maternally-derived antibodies were lower for premature babies, reflecting reduced transplacental antibody transfer at earlier gestations [30,31], and higher for mothers with older children, who are likely to introduce RSV infections into households $[11,13,28]$. Since the majority of RSV-related hospitalisations occur in term babies $[6,7]$, our findings suggest that pregnant women with older children are a particularly important group for targeting via maternal vaccination programmes.

\section{Conclusions}

We have shown that $53 \%$ of children in England are infected with RSV during the first year of life, and $14 \%$ remain uninfected by age 2 . Between birth and 2 years old, the proportion of RSV infected children who seek primary or secondary healthcare does not decrease with age. Our study, based on secondary analyses of blood samples and linked data, present a time-efficient and cheap method for carrying out serological surveys to determine the community burden of disease due to RSV in young children.

\section{Acknowledgements}

This article is dedicated to Professor Harvey Goldstein, who sadly passed away before this manuscript was published. Professor Goldstein was an internationally renowned statistician and social science researcher, perhaps best known for his seminal work on methodology and software for multilevel modelling. He was also a generous colleague and collaborator, and he will be greatly missed.

Born in Bradford is only possible because of the enthusiasm and commitment of the children and parents in Born in Bradford. We are grateful to all participants, health professionals and researchers who have made Born in Bradford happen.

Funding: This project was supported by a Wellcome Trust Seed Award In Science, grant reference number 207673/Z/17/Z. The funders had no role in study design, data collection and analysis, decision to publish, or preparation of the manuscript. Research at UCL Great Ormond Street Institute of Child Health is supported by the NIHR Great Ormond Street Hospital Biomedical Research Centre.

Conflict of interest

None declared.

Authors' contributions

$\mathrm{PH}$ conceptualised the study with support from HG, RoS, LP and CS. DM and JW provided the data extract for this study. 
GB, RuS, FvdK carried out serological testing. AZ cleaned and analysed the data with support from PH, LP, HG. AZ and $\mathrm{PH}$ wrote the first draft of the manuscript. All authors contributed to writing and finalising the manuscript.

\section{References}

1. Shi T, McAllister DA, O’Brien KL, Simoes EAF, Madhi SA, Gessner BD, et al. , RSV Global Epidemiology Network. Global, regional, and national disease burden estimates of acute lower respiratory infections due to respiratory syncytial virus in young children in 2015: a systematic review and modelling study. Lancet. 2017;390(10098):946-58. https://doi. org/10.1016/S0140-6736(17)30938-8 PMID: 28689664

2. Nair H, Nokes DJ, Gessner BD, Dherani M, Madhi SA, Singleton RJ, et al. Global burden of acute lower respiratory infections due to respiratory syncytial virus in young children: a systematic review and meta-analysis. Lancet. 2010;375(9725):1545-55. https://doi.org/10.1016/S01406736(10)60206-1 PMID: 20399493

3. NHS Digital. Hospital Admitted Patient Care Activity, 2017-18 - NHS Digital. England. 2018 [Accessed 12 Feb 2019]. Available from: https://digital.nhs. uk/data-and-information/publications/statistical/ hospital-admitted-patient-care-activity/2017-18

4. Wu P, Hartert TV. Evidence for a causal relationship between respiratory syncytial virus infection and asthma. Expert Rev Anti Infect Ther. 2011;9(9):731-45. https://doi.org/10.1586/ eri.11.92 PMID: 21905783

5. PATH Vaccine Resource Library. RSV Vaccine and $m A b$ Snapshot. [Accessed 31 May 2019]. Available from: https:// vaccineresources.org/details.php?i=1562

6. Hardelid P, Verfuerden M, McMenamin J, Smyth RL, Gilbert R. The contribution of child, family and health service factors to respiratory syncytial virus (RSV) hospital admissions in the first 3 years of life: birth cohort study in Scotland, 2009 to 2015 . Euro Surveill. 2019;24(1):1800046. https://doi. org/10.2807/1560-7917.ES.2019.24.1.1800046 PMID: 30621817

7. Murray J, Bottle A, Sharland M, Modi N, Aylin P, Majeed $A$, et al. , Medicines for Neonates Investigator Group. Risk factors for hospital admission with RSV bronchiolitis in England: a population-based birth cohort study. PLoS One. 2014;9(2):e89186. https://doi.org/10.1371/journal. pone.0089186 PMID: 24586581

8. Hall CB, Walsh EE, Long CE, Schnabel KC. Immunity to and frequency of reinfection with respiratory syncytial virus. J Infect Dis. 1991;163(4):693-8. https://doi.org/10.1093/ infdis/163.4.693 PMID: 2010624

9. Reeves RM, Hardelid P, Gilbert R, Warburton F, Ellis J, Pebody RG. Estimating the burden of respiratory syncytial virus (RSV) on respiratory hospital admissions in children less than five years of age in England, 2007-2012. Influenza Other Respir Viruses. 2017;11(2):122-9. https://doi.org/10.1111/irv.12443 PMID: 28058797

10. Hogan AB, Anderssen RS, Davis S, Moore HC, Lim FJ, Fathima P, et al. Time series analysis of RSV and bronchiolitis seasonality in temperate and tropical Western Australia. Epidemics. 2016;16:49-55. https://doi.org/10.1016/j.epidem.2016.05.001 PMID: 27294794

11. Poletti P, Merler S, Ajelli M, Manfredi P, Munywoki PK, Nokes $D$, et al. Evaluating vaccination strategies for reducing infant respiratory syncytial virus infection in low-income settings. BMC Med. 2015;13(1):49. https://doi.org/10.1186/s12916-0150283-x PMID: 25857701

12. Kinyanjui TM, House TA, Kiti MC, Cane PA, Nokes DJ, Medley GF. Vaccine Induced Herd Immunity for Control of Respiratory Syncytial Virus Disease in a Low-Income Country Setting. PLoS One. 2015;10(9):e0138018. https://doi.org/10.1371/journal. pone.0138018 PMID: 26390032

13. Hall CB, Geiman JM, Biggar R, Kotok DI, Hogan PM, Douglas GR Jr. Respiratory syncytial virus infections within families. N Engl J Med. 1976;294(8):414-9. https://doi.org/10.1056/ NEJM197602192940803 PMID: 173995

14. Glezen WP, Taber LH, Frank AL, Kasel JA. Risk of primary infection and reinfection with respiratory syncytial virus. Am Dis Child. 1986;140(6):543-6. PMID: 3706232

15. Kutsaya A, Teros-Jaakkola T, Kakkola L, Toivonen L, Peltola V, Waris $M$, et al. Prospective clinical and serological follow-up in early childhood reveals a high rate of subclinical RSV infection and a relatively high reinfection rate within the first 3 years of life. Epidemiol Infect. 2016;144(8):1622-33. https://doi. org/10.1017/So950268815003143 PMID: 26732801

16. Wright J, Small N, Raynor P, Tuffnell D, Bhopal R, Cameron N, et al. , Born in Bradford Scientific Collaborators Group. Cohort
Profile: the Born in Bradford multi-ethnic family cohort study. Int J Epidemiol. 2013;42(4):978-91. https://doi.org/10.1093/ ije/dys112 PMID: 23064411

17. Pembrey L, Waiblinger D, Griffiths P, Patel M, Azad R, Wright J. Cytomegalovirus, Epstein-Barr virus and varicella zoster virus infection in the first two years of life: a cohort study in Bradford, UK. BMC Infect Dis. 2017;17(1):220. https://doi. org/10.1186/s12879-017-2319-7 PMID: 28320319

18. Schepp RM, de Haan CAM, Wilkins D, Layman H, Graham BS, Esser MT, et al. Development and Standardization of a HighThroughput Multiplex Immunoassay for the Simultaneous Quantification of Specific Antibodies to Five Respiratory Syncytial Virus Proteins. MSphere. 2019;4(2):e00236-19. https://doi.org/10.1128/mSphere.00236-19 PMID: 31019002

19. Hardelid P, Williams D, Dezateux C, Tookey PA, Peckham CS, Cubitt WD, et al. Analysis of rubella antibody distribution from newborn dried blood spots using finite mixture models. Epidemiol Infect. 2008;136(12):1698-706. https://doi. org/10.1017/S0950268808000393 PMID: 18294427

20. Vyse AJ, Gay NJ, Hesketh LM, Pebody R, Morgan-Capner $P$, Miller E. Interpreting serological surveys using mixture models: the seroepidemiology of measles, mumps and rubella in England and Wales at the beginning of the $21 \mathrm{st}$ century. Epidemiol Infect. 2006;134(6):1303-12. https://doi. org/10.1017/So950268806006340 PMID: 16650326

21. Zou G. A modified Poisson regression approach to prospective studies with binary data. Am J Epidemiol. 2004;159(7):702-6. https://doi.org/10.1093/aje/kwho9o PMID: 15033648

22. Brandenburg AH, Groen J, van Steensel-Moll HA, Claas EC, Rothbarth PH, Neijens HJ, et al. Respiratory syncytial virus specific serum antibodies in infants under six months of age: limited serological response upon infection. J Med Virol. 1997;52(1):97-104. https://doi.org/10.1002/(SICI)10969071(199705)52:1<97::AID-JMV16>3.0.CO;2-Y PMID: 9131465

23. Ochola R, Sande C, Fegan G, Scott PD, Medley GF, Cane PA, et al. The level and duration of RSV-specific maternal IgG in infants in Kilifi Kenya. PLoS One. 2009;4(12):e8088. https:// doi.org/10.1371/journal.pone.0008088 PMID: 19956576

24. Sande CJ, Cane PA, Nokes DJ. The association between age and the development of respiratory syncytial virus neutralising antibody responses following natural infection in infants. Vaccine. 2014;32(37):4726-9. https://doi.org/10.1016/j. vaccine.2014.05.038 PMID: 25005882

25. Rubin DB. Multiple imputation for nonresponse in surveys. New York: Wiley; 1987.

26. Ohuma EO, Okiro EA, Ochola R, Sande CJ, Cane PA, Medley $\mathrm{GF}$, et al. The natural history of respiratory syncytial virus in a birth cohort: the influence of age and previous infection on reinfection and disease. Am J Epidemiol. 2012;176(9):794-802. https://doi.org/10.1093/aje/kwS257 PMID: 23059788

27. Nyiro JU, Kombe IK, Sande CJ, Kipkoech J, Kiyuka PK, Onyango $\mathrm{CO}$, et al. Defining the vaccination window for respiratory syncytial virus (RSV) using age-seroprevalence data for children in Kilifi, Kenya. PLoS One. 2017;12(5):e0177803. https://doi.org/10.1371/journal.pone.0177803 PMID: 28531224

28. Munywoki PK, Koech DC, Agoti CN, Lewa C, Cane PA, Medley $\mathrm{GF}$, et al. The source of respiratory syncytial virus infection in infants: a household cohort study in rural Kenya. J Infect Dis. 2014;209(11):1685-92. https://doi.org/10.1093/infdis/jit828 PMID: 24367040

29. Stensballe LG, Ravn H, Kristensen K, Meakins T, Aaby $P$, Simoes EAF. Seasonal variation of maternally derived respiratory syncytial virus antibodies and association with infant hospitalizations for respiratory syncytial virus. J Pediatr. 2009;154(2):296-8e1. https://doi.org/10.1016/j. jpeds.2008.07.053 PMID: 19150677

30. Okoko JB, Wesumperuma HL, Hart CA. The influence of prematurity and low birthweight on transplacental antibody transfer in a rural West African population. Trop Med Int Health. 2001;6(7):529-34. https://doi.org/10.1046/j.13653156.2001.00741.x PMID: 11469946

31. Chu HY, Steinhoff MC, Magaret A, Zaman K, Roy E, Langdon $\mathrm{G}$, et al. Respiratory syncytial virus transplacental antibody transfer and kinetics in mother-infant pairs in Bangladesh. J Infect Dis. 2014;210(10):1582-9. https://doi.org/10.1093/ infdis/jiuz16 PMID: 24903663

\section{License, supplementary material and copyright}

This is an open-access article distributed under the terms of the Creative Commons Attribution (CC BY 4.0) Licence. You may share and adapt the material, but must give appropriate 
credit to the source, provide a link to the licence and indicate if changes were made.

Any supplementary material referenced in the article can be found in the online version.

This article is copyright of the authors or their affiliated institutions, 2021. 